\title{
Meta Model BASEd Evolutionary OPTIMIZATION
}

\author{
BHATTACHARYA, M.
}

Abstract: Evolutionary algorithms (EAs) have proven to be powerful optimizers which make them excellent candidates to solve complex optimization problems such as engineering design optimization problems. However, population based iterative techniques such as evolutionary algorithms require numerous evaluations of candidate solutions. For many real world optimization problems such evaluations may take hours to days of computation, making use of iterative techniques such as EA unfeasible. Reducing the number of such evaluations without compromising much on the solution accuracy is the only feasible means to solve this problem. In this chapter we briefly detail various tools which can be used to build the approximation models for fitness function approximation in evolutionary algorithms. We further present the special scenario where the solution space is inflicted by uncertainty. A brief discussion on such uncertain environment has been included. Simulation results from application of the enhanced Dynamic Approximate Fitness based Hybrid Evolutionary Algorithm (DAFHEA - II) to such problems have been presented.

Key words: Design optimization, Evolutionary Algorithm, Approximation, Approximation model, Global optimizer
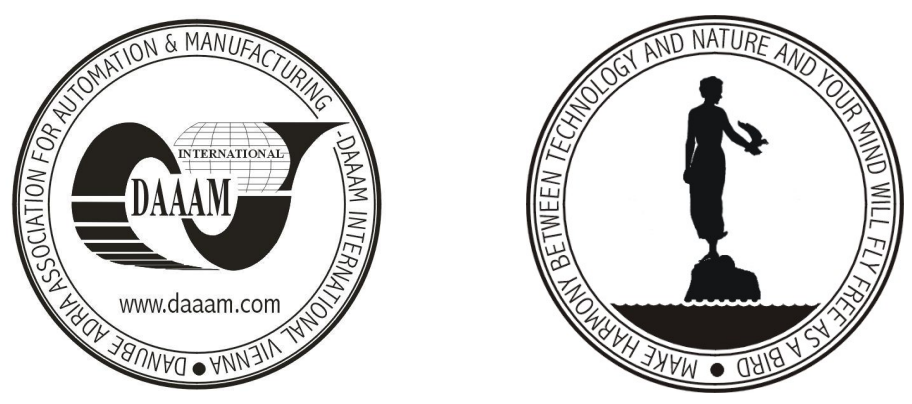

Authors' data: Bhattacharya, M[aumita], Charles Sturt University, PO Box: 789 Albury, NSW 2640, Australia, maumita.bhattacharya@ieee.org

This Publication has to be referred as: Bhattacharya, M. (2007). Meta Model Based Evolutionary Optimization, Chapter 56 in DAAAM International Scientific Book 2007, B. Katalinic (Ed.), Published by DAAAM International, ISBN 3-90150960-7, ISSN 1726-9687, Vienna, Austria

DOI: $10.2507 /$ daaam.scibook.2007.56 